\title{
Response to: Surgery-Related Complications and Sequelae in Management of Tuberculosis of Spine
}

\author{
Safak Ekinci ${ }^{1}$, Faruk Akyildiz ${ }^{2}$, Omer Ersen ${ }^{3}$ \\ ${ }^{1}$ Department of Orthopaedic Surgery, Agri Military Hospital, Agri, Turkey \\ ${ }^{2}$ Department of Orthopaedic Surgery, Malatya Military Hospital, Malatya, Turkey \\ ${ }^{3}$ Department of Orthopaedic Surgery, Erzurum Military Hospital, Erzurum, Turkey
}

Dear Editor,

We read the published article by Moon et al. [1] entitled "Surgery-Related Complications and Sequelae in Management of Tuberculosis of Spine" with great interest. The authors said "surgery should be reserved only for the complicated cases of spinal tuberculosis in patients for whom surgery is definitely indicated" [1].

However, we think that some more points should be discussed regarding therapy planning.

Spinal tuberculosis is the most common and the worst form of tuberculosis lesions in the skeleton [2-4]. If the lesion is limited within the vertebrae, and if there are no complications, triple-drug anti-tuberculous chemotherapy can be the main therapy to treat tuberculosis [5]. However, with proper indications, surgical procedures are superior in the prevention of neurological deterioration, maintenance of stability, and early recovery [3-6].

Oguz et al. [4] reported 76 cases with spinal tuberculosis resulted in excellent recoveries without any neurological deterioration. As a result, they developed an effective classification system named GATA.

We believe that this new classification system should be considered as a practical guide for spinal tuberculosis treatment planning in all countries.

\section{Conflict of Interest}

No potential conflict of interest relevant to this article was reported.

\section{References}

1. Moon MS, Kim SS, Moon YW, Moon H, Kim SS. Surgery-related complications and sequelae in management of tuberculosis of spine. Asian Spine J 2014;8:435-45

2. Boachie-Adjei O, Squillante RG. Tuberculosis of the spine. Orthop Clin North Am 1996;27:95-103.

3. Rezai AR, Lee M, Cooper PR, Errico TJ, Koslow M. Modern management of spinal tuberculosis. Neurosurgery 1995;36:87-97.

4. Oguz E, Sehirlioglu A, Altinmakas M, et al. A new classification and guide for surgical treatment of spinal tuberculosis. Int Orthop 2008;32:127-33.

5. Moon MS, Moon YW, Moon JL, Kim SS, Sun DH.

Received Oct 26, 2014; Revised Oct 26, 2014; Accepted Oct 28, 2014

Corresponding author: Safak Ekinci

Department of Orthopaedic Surgery, Agri Military Hospital, Agri, Turkey

Tel: +90-532-733-98-50, Fax: +90-472-215-27-47, E-mail: safakekinci@yahoo.com 
Conservative treatment of tuberculosis of the lumbar and lumbosacral spine. Clin Orthop Relat Res 2002;(398):40-9.

6. Ghadouane M, Elmansari O, Bousalmame N, Lez- rek K, Aouam H, Moulay I. Role of surgery in the treatment of Pott's disease in adults. Apropos of 29 cases. Rev Chir Orthop Reparatrice Appar Mot 1996;82:620-8. 